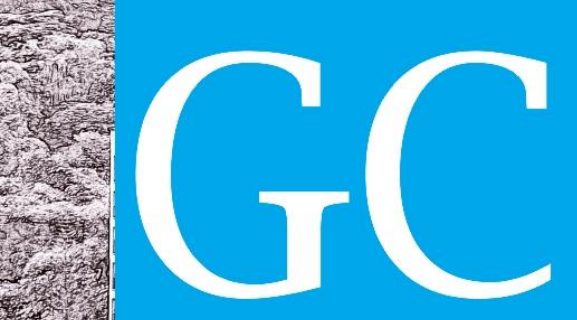

\title{
Logística reversa de resíduos eletroeletrônicos no setor de assistências técnicas e comércio de equipamentos eletroeletrônicos na cidade de Ponta Grossa-Pr
}

Reverse logistic of electrical and electronic equipment waste on the technical assistance sector and trade of electrical and electronic in the city of Ponta Grossa

Logística inversa de residuos electrónicos en el sector de asistencia técnica y comercio de equipos electrónicos en la ciudad de Ponta Grossa

Nathan Streisky da Silva Mestrando em Engenharia Ambiental, UFPR, Brasil nathanstreisky@gmail.com

Tatiane Bonametti Veiga Professora adjunta, UNICENTRO, Brasil tati.veiga@yahoo.com.br 


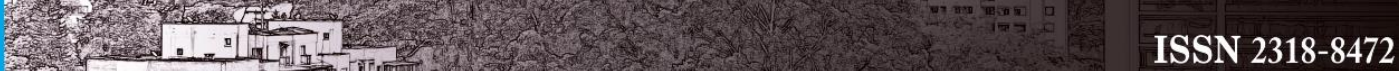

Revista Nacional de

Gerenciamento de Cidades

\section{INTRODUÇÃO}

Os equipamentos eletroeletrônicos tornaram-se parte essencial das atividades humanas nos últimos tempos. Entretanto, nos anos mais recentes foi possível perceber um crescimento extraordinário na tecnologia dos aparelhos, principalmente nos eletroeletrônicos de pequeno porte como celulares, notebooks, smartphones. Esses fatores, aliados a uma maior distribuição da informação e melhorias em ramos como o marketing, tem levado as pessoas a consumirem um número maior de produtos, fato que acaba exercendo uma pressão no fluxo geral e na geração de resíduos de equipamentos eletroeletrônicos (REEE) (HENRIQUE JÚNIOR et al., 2013; ROCHMAN; ASHTON; WIHARJO, 2017).

Assim, a geração de "lixo eletrônico" tem crescido mundialmente. O relatório "Global E-Waste Monitor 2017", publicado pela Universidade das Nações Unidas (United Nations University - UNU), União Internacional de Telecomunicação (International Telecomunication Union - ITU) e Associação Internacional de Resíduos Sólidos (International Solid Waste Association - ISWA), mostrou que foram gerados 44,7 milhões de toneladas de REEE, no ano de 2016. Desse montante, apenas $20 \%$ era coletado, documentado e devidamente reciclado. A partir da projeção dos dados, com base nos anos anteriores, até o ano de 2021 seriam gerados 52,2 milhões de toneladas, aproximadamente, em todo o mundo. Segundo o mesmo relatório, no ano de 2016, foram gerados, no Brasil, cerca de 1,5 milhões de toneladas de resíduos de equipamentos eletroeletrônicos (BALDÉ et al., 2017).

Diversos problemas podem estar relacionados com esta produção em massa de novos equipamentos, entretanto, dois podem ser considerados mais importantes no que diz respeito a área ambiental, sendo eles: a quantidade de recursos naturais a ser utilizada para a confecção desses produtos (PAIVA; SERRA, 2014); e o tratamento e disposição final adequada dos equipamentos obsoletos ou dos resíduos provenientes dos mesmos, onde um dos agravantes desses processos, é heterogeneidade de materiais que compõem os equipamentos e seus respectivos resíduos, que podem ser constituídos de metais como Ferro (Fe), Cobre $(\mathrm{Cu})$, Chumbo $(\mathrm{Pb})$, Ouro $(\mathrm{Au})$ e Prata $(\mathrm{Ag})$, e diversos tipos de plásticos e cerâmicas, o que dificulta a gestão dos mesmos (CUI; ZHANG, 2008; PARK; FRAY, 2009).

Diversos trabalhos têm sido realizados com intuito de amenizar tais problemas, assim como a elaboração de normas e legislações em diversos países do mundo, objetivando melhorar a gestão, o tratamento e a disposição final ambientalmente adequada dos equipamentos eletroeletrônicos obsoletos e seus respectivos resíduos (ONGONDO; WILLIANMS; CHERRETT, 2011; YAMANE, 2012).

No Brasil, no que diz respeito a área de resíduos sólidos, foi publicada no dia 2 de agosto de 2010 , a Lei no 12.305, que instituiu a Política Nacional de Resíduos Sólidos (PNRS). Essa lei estabelece diretrizes relativas à gestão integrada e ao gerenciamento de resíduos sólidos, bem como normas para redução, reciclagem e reutilização (BRASIL, 2010).

Na PNRS é estabelecido, em seu inciso IV do art. 33, que os fabricantes, importadores, distribuidores e comerciantes de equipamentos eletroeletrônicos devem implementar sistemas de logística reversa após o retorno do produto pelo consumidor, sendo esse processo realizado de forma separada ao serviço urbano de limpeza pública (BRASIL, 2010). Dentro desse contexto, a logística reversa, é definida como:

Instrumento de desenvolvimento econômico e social caracterizado por um conjunto de ações, procedimentos e meios destinados a viabilizar a coleta e a restituição dos resíduos sólidos ao setor 


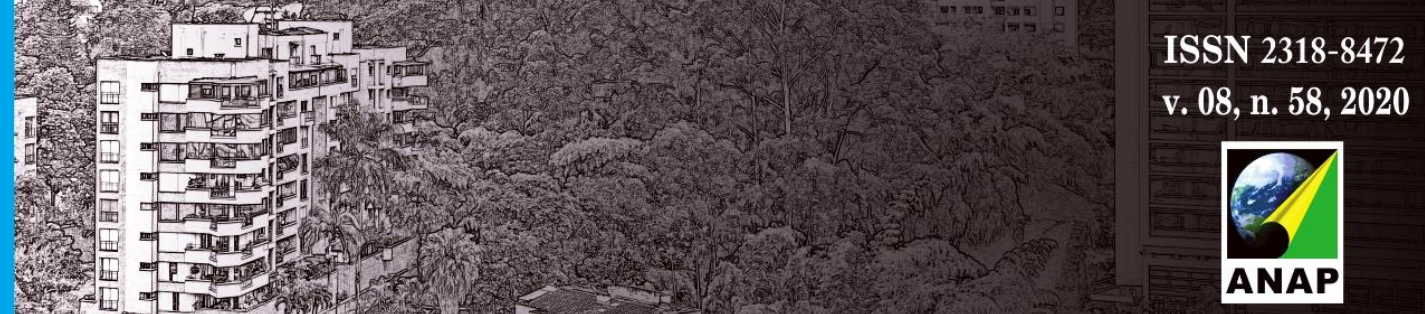

Revista Nacional de Gerenciamento de Cidades

empresarial, para reaproveitamento, em seu ciclo ou em outros ciclos produtivos, ou outra destinação final ambientalmente adequada (BRASIL, 2010, p.2).

Esse conceito enquadra-se como um importante e viável instrumento do gerenciamento do curso dos REEE após seu consumo, bem como a sua volta pela cadeia reversa, e a partir disso, a possibilidade de sua reutilização ou reciclagem de componentes, ou até mesmo a extração de matérias-primas para confecção de novos produtos (QUINTANA; BENETTI, 2016; SELPIS; CASTILHO; ARAÚJO, 2012).

No estado do Paraná, a Lei Estadual no 15.851, publicada no dia 10 de junho de 2008, no Diário Oficial do Estado do Paraná:

Dispõe que as empresas produtoras, distribuidoras e que comercializam equipamentos de informática, instaladas no Estado do Paraná, ficam obrigadas a criar e manter o Programa de Recolhimento, Reciclagem ou Destruição de Equipamentos de Informática, sem causar poluição ambiental, conforme especifica (PARANÁ, 2008, p.1).

No dia 12 de fevereiro de 2020, o decreto no 10.240 foi publicado regulamentando o referido art. 33 "quanto a implementação de sistema de logística reversa de produtos eletroeletrônicos e seus componentes de uso doméstico" (BRASIL, 2020, p. 1). Tal decreto é um grande avanço no que tange a gestão integrada de REEE, pois aborda desde a estruturação até a operacionalização de sistemas de logística reversa.

Esse decreto reforça a importância de um dos conceitos apresentados pela PNRS, que consiste na definição de responsabilidade compartilhada pelo ciclo de vida dos produtos, sendo definido pela própria política, como:

Conjunto de atribuições individualizadas e encadeadas dos fabricantes, importadores, distribuidores e comerciantes, dos consumidores e dos titulares dos serviços públicos de limpeza urbana e de manejo dos resíduos sólidos, para minimizar o volume de resíduos sólidos e rejeitos gerados, bem como para reduzir os impactos causados à saúde humana e à qualidade ambiental decorrentes do ciclo de vida dos produtos (BRASIL, 2010, p.2).

Assim, o bom funcionamento de toda a cadeia de logística reversa, está intimamente relacionado a responsabilidade compartilhada, já que é um processo que vai desde após o uso do produto pelo consumidor, até o tratamento ou destinação final adequada. Sendo assim, os REEE são passíveis de logística reversa.

Nesse contexto, o presente trabalho teve como objetivo elaborar um diagnóstico a situação da gestão integrada dos resíduos de equipamentos eletroeletrônicos de pequeno e médio porte e a logística reversa desses resíduos no setor de comércio e assistências na cidade de Ponta Grossa no Paraná.

\section{METODOLOGIA}

O trabalho consistiu em uma pesquisa descritiva exploratória com a aplicação de um questionário com questões elaboradas a fim de obter a opinião dos sujeitos responsáveis pelo comércio e assistências técnicas a respeito da gestão integrada dos resíduos de equipamentos eletroeletrônicos.

As pesquisas descritivas visam descrever os aspectos de um determinado público ou fenômeno e as relações entre as suas variáveis. Os estudos realizados sob esta designação, geralmente são caracterizados pelas técnicas padronizadas de coleta, sendo elas na forma de questionários e observações sistemáticas (GIL, 2002; SILVA; MENEZES, 2005). Já as pesquisas exploratórias têm como objetivo proporcionar maior familiaridade 


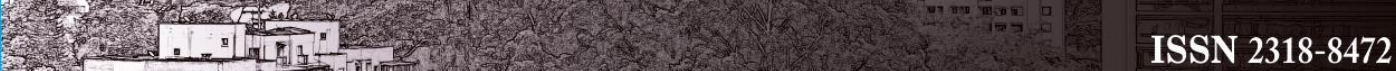

Revista Nacional de

Gerenciamento de Cidades

com o problema, para torná-lo mais explícito e possibilitar a sua definição e o seu delineamento (PRODANOV; FREITAS, 2013).

A pesquisa foi realizada na cidade de Ponta Grossa, com uma população estimada, no ano de 2019, em 351.736 habitantes (IBGE, 2010), localizada na região dos Campos Gerais no Paraná.

Para a realização do trabalho, foi aplicado um questionário com 11 perguntas fechadas, organizadas em uma escala do tipo Likert, que foram entregues aos responsáveis pelo setor de logística reversa da empresa. Os questionários foram aplicados em assistências técnicas de eletroeletrônicos de pequeno porte (celulares, notebooks, smartphones) e médio porte (computadores de mesa, entre outros).

A elaboração do instrumento utilizado para realização dessa pesquisa foi fundamentada em uma pesquisa na área de logística reversa de resíduos eletrônicos do setor de informática na cidade de Natal (SILVA; PIMENTA; CAMPOS, 2013), sendo realizado um estudo piloto para adequar o instrumento às especificidades regionais. O estudo piloto foi realizado para possíveis adaptações no questionário e seus resultados não foram contabilizados para os resultados finais.

Para o desenvolvimento da pesquisa, foi realizado um levantamento dos possíveis empreendimentos passíveis de produção de resíduos de equipamentos eletroeletrônicos, tendo como base a lista de empresas associadas a Associação Comercial, Industrial e Empresarial de Ponta Grossa, sendo que essa lista foi obtida no site oficial da associação (ACIPG, 2018). Após a listagem inicial de empresas, foram constatadas a existência de 40 estabelecimentos individuais e 1 um shopping (com 10 locais passíveis de geração de resíduos sólidos), que se encaixavam no escopo desse estudo, totalizando um universo de 50 locais.

Do número inicial de empresas encontradas, $24 \%$ não foram localizadas devido a uma desatualização dos dados; $30 \%$ não se encaixavam no escopo do trabalho por não atuarem com empreendimentos passíveis da geração de resíduos eletroeletrônicos devido a atividade de assistência técnica; $2 \%$ dos estabelecimentos trabalhavam com a produção de software para computadores e $6 \%$ locais optaram por não participar da pesquisa. Dessa forma, para o desenvolvimento dessa pesquisa e considerando as implicações anteriormente descritas, foram considerados os dados levantados em $38 \%$ comércio/assistências de EEE a partir da aplicação dos questionários.

O estudo foi realizado na área destinada para atendimento ao público sendo que os sujeitos, os quais responderam o questionário, correspondiam aos funcionários do estabelecimento que tinham algum conhecimento sobre o funcionamento de todo o sistema de gestão de resíduos da empresa, sendo este um requisito para que as perguntas fossem respondidas da forma mais representativa possível. Em todos os locais, a pessoa que se disponibilizou para responder a pesquisa consistia no gerente e/ou responsável pelo estabelecimento em questão.

Após a coleta, os dados foram duplamente digitados, a fim de evitar possíveis erros de transcrição e apresentados na forma de tabelas para sintetizar e evidenciar todos os aspectos, buscando fornecer o máximo de informações de forma clara e coerente, visando um melhor entendimento da situação e também para a permitir a formulação de sugestões para as questões levantadas (PRODANOV; FREITAS, 2013).

Para análise dos dados, a apresentação dos resultados obtidos foi dividida em três partes, segundo as temáticas abordadas no questionário, sendo elas: o Nível de Consciência sobre Resíduos de Equipamentos Eletroeletrônicos, Desenvolvimento da Empresa em Relação a Práticas de Gestão Ambiental e Desenvolvimento de um Plano de Gestão de Resíduos de Equipamentos Eletrônicos. 
O projeto foi submetido ao Comitê de Ética em Pesquisa (CEP) da Universidade Estadual do Centro-Oeste (UNICENTRO), segundo a Resolução 466/12 (BRASIL, 2012), aprovado com Certificado de Apresentação para Apreciação Ética (CAAE) no 79740817.4.0000.0106, e parecer 2.390.052, em 21 de novembro de 2017. Todos os sujeitos convidados para participar da pesquisa, assinaram e devolveram o Termo de Consentimento Livre e Esclarecido (TCLE) antes do início de sua participação.

\section{RESULTADOS E DISCUSSÃO}

\subsection{Nível de consciência sobre resíduos eletroeletrônicos}

Em um plano histórico, a consciência ambiental de uma forma geral, teve início apenas nas últimas décadas, principalmente após os anos 70, quando surgiram os grandes debates ambientalistas, e a partir desse ponto, os conceitos de gestão ambiental e sustentabilidade obtiveram um maior destaque nas discussões mundiais. Após esses acontecimentos, a conscientização ambiental sobre diversos problemas, como a geração de resíduos, tem aumentado e vem abrangendo toda a cadeia produtiva como fabricantes, comércios e consumidores, tornando-se mais presente em no cotidiano da sociedade como um todo (MOTA et al., 2016) e fazendo parte das políticas administrativas de vários municípios brasileiros.

Nesse contexto, a consciência ambiental da população, em geral, busca uma maior adequação ao cenário no que tange a gestão REEE, sendo assim, esse nível de consciência foi estudado e os resultados obtidos apresentados na tabela 1.

Tabela 1 - Nível de consciência sobre os resíduos de equipamentos eletroeletrônicos

\begin{tabular}{|c|c|c|c|c|c|}
\hline & $\begin{array}{l}\text { Muito } \\
\text { pouco }\end{array}$ & Pouco & Razoável & Bom & $\begin{array}{l}\text { Muito } \\
\text { Bom }\end{array}$ \\
\hline $\begin{array}{c}\text { Consciência sobre a responsabilidade pelo recolhimento e } \\
\text { tratamento dos resíduos eletroeletrônicos }\end{array}$ & $0 \%$ & $0 \%$ & $11 \%$ & $32 \%$ & $58 \%$ \\
\hline $\begin{array}{l}\text { Consciência sobre importância de incentivar o uso do } \\
\text { equipamento até o fim da sua vida útil. }\end{array}$ & $0 \%$ & $0 \%$ & $5 \%$ & $42 \%$ & $53 \%$ \\
\hline $\begin{array}{l}\text { Consciência sobre a importância de realizar a reciclagem dos } \\
\text { produtos eletroeletrônicos }\end{array}$ & $0 \%$ & $0 \%$ & $16 \%$ & $32 \%$ & $53 \%$ \\
\hline $\begin{array}{l}\text { Consciência sobre a importância de se priorizar fabricantes que } \\
\text { possuam uma política de incentivo de retorno dos produtos } \\
\text { após o consumo }\end{array}$ & $5 \%$ & $11 \%$ & $32 \%$ & $26 \%$ & $26 \%$ \\
\hline
\end{tabular}

Fonte: Os autores (2018).

O nível de consciência em relação aos REEE refere-se ao conhecimento das empresas sobre o que se pode fazer para minimizar a geração de REEE, ou sobre a responsabilidade compartilhada dos mesmos. Essa abordagem na pesquisa está diretamente relacionada às questões mais habituais de educação ambiental, como reciclagem e uso do equipamento até o final da vida útil.

A compreensão sobre a importância da gestão de REEE encontra-se relacionada a uma das esferas da consciência ambiental, podendo ser definida como "a tendência de um determinado indivíduo se posicionar 


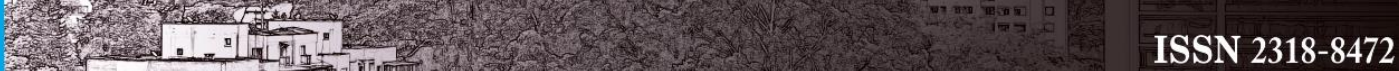

Revista Nacional de

Gerenciamento de Cidades

a favor ou contra quando colocado diante de assuntos relativos ao meio ambiente. Deste modo, indivíduos com uma maior consciência ambiental, tomariam decisões levando em conta o impacto ambiental das mesmas" (BEDANTE; SLONGO, 2004, p.3).

Nessa vertente, a maioria dos sujeitos apresentou um bom conhecimento sobre questões de consciência ambiental, sendo que o único item com respostas mais desfavoráveis, foi referente a priorização de fabricantes com política de incentivo pós-consumo, o qual é um ponto muito importante a ser discutido quando se refere à logística reversa, já que uma de suas premissas básicas seria a responsabilidade compartilhada, a qual, se manifesta na gestão dos REEE, justamente por meio de programas de logística reversa, onde os comerciantes poderiam encaminhar os resíduos, para empresas especializadas no reaproveitamento ou destinação ambientalmente adequada dos mesmos (BRASIL, 2010; PORTO et al., 2018).

A utilização dos equipamentos eletroeletrônicos até o fim da sua vida útil, fortemente atrelada ao conceito de sustentabilidade, principalmente em relação ao uso consciente dos recursos naturais, pode ser conseguida de diversas maneiras, sendo que uma das mais utilizadas correspondem às atualizações dos equipamentos (mais comum em celulares e computadores) ou "upgrades", onde o sistema de funcionamento do aparelho (podendo ser feito em partes, ou para o sistema como um todo) é substituído por uma nova versão e mais atualizada, tirando assim do consumidor, a necessidade da aquisição de um novo equipamento (TRUTTMANN; RECHBERGER, 2006).

Os participantes demonstraram certo conhecimento nesse item, provavelmente devido as questões sobre educação ambiental serem mais facilmente transportadas de outras áreas do conhecimento, como por exemplo a gestão dos resíduos sólidos urbanos ou, de embalagens de agrotóxicos (outro item obrigatório da logística reversa amparado pela PNRS), sendo essa, melhor desenvolvida no Brasil, principalmente devido ao conjunto de legislações elaboradas e consolidadas para o setor (LADEIRA; MAEHLER; NASCIMENTO, 2012).

Outro fator a ser destacado, corresponde ao uso dos equipamentos eletroeletrônicos até o final da sua vida útil, que pode diminuir de forma expressiva a destinação de tais produtos para aterros sanitários, além de ajudar a estender sua vida útil dos mesmos, sendo uma outra problemática de abordagem complexa no mundo atual (SILVA; PIMENTA; CAMPOS, 2013).

\subsection{Desenvolvimento da empresa em relação a práticas de gestão ambiental}

O tema gestão ambiental teve início no século XVIII, com a Revolução Industrial, visto que desde essa época o planeta tem sofrido as consequências dos avanços tecnológicos. Após várias conferências de grande repercussão, como a Conferência das Nações Unidas Sobre o Meio Ambiente Humano, em Estocolmo, no ano 1972, e a "Rio-92" no Rio de Janeiro, em 1992, diversos países começaram a criar as leis, que tem por objetivo conter a degradação ambiental. Posteriormente, para se adequar as novas normas e também conseguir uma imagem de instituição ecologicamente responsável, empresas começaram a adotar uma nova forma de gestão, a qual conhecemos hoje por gestão ambiental (ALVES; BARBOSA, 2013; OLEGÁRIO; COLARES-SANTOS; ZAGO, 2015).

Atualmente, uma das diversas definições de gestão ambiental consiste em:

Um processo contínuo e adaptativo, no qual a empresa adéqua suas metas e objetivos com relação à proteção do ambiente, à saúde e à segurança de seus empregados, clientes e comunidade, definindo e redefinindo estratégias e recursos para atingir os objetivos definidos para um determinado prazo, através da constante troca com o meio ambiente externo (SILVA FILHO, 2008, p.7). 
Revista Nacional de

Gerenciamento de Cidades

Nesse contexto, o presente trabalho buscou a abordagem dessa temática fundamental, sendo apresentado os resultados obtidos a partir das respostas dos sujeitos em relação a algumas práticas de gestão quanto a REEE em seus estabelecimentos (Tabela 2).

Tabela 2: Desenvolvimento da empresa em relação a práticas de gestão ambiental

\begin{tabular}{|c|c|c|c|c|c|}
\hline & Nunca & $\begin{array}{l}\text { Quase } \\
\text { nunca }\end{array}$ & $\begin{array}{l}\text { Algumas } \\
\text { Vezes }\end{array}$ & $\begin{array}{l}\text { Quase } \\
\text { Sempre }\end{array}$ & Sempre \\
\hline $\begin{array}{l}\text { Frequência em que prioriza fabricantes com política de } \\
\text { retorno pós consumo }\end{array}$ & $16 \%$ & $21 \%$ & $42 \%$ & $11 \%$ & $11 \%$ \\
\hline $\begin{array}{l}\text { Frequência da realização de ações voltadas para a } \\
\text { educação ambiental com funcionários informando sobre } \\
\text { as questões ambientais dentro da atividade da empresa e } \\
\text { alertando sobre os riscos dos REEE e necessidade de } \\
\text { reciclagem }\end{array}$ & $0 \%$ & $21 \%$ & $21 \%$ & $21 \%$ & $37 \%$ \\
\hline $\begin{array}{l}\text { Frequência de implementação de campanhas de } \\
\text { conscientização ambiental junto aos clientes relacionados } \\
\text { ao recolhimento dos resíduos eletroeletrônicos }\end{array}$ & $16 \%$ & $16 \%$ & $32 \%$ & $16 \%$ & $21 \%$ \\
\hline $\begin{array}{l}\text { Frequência da aplicação de regulamentos, normas ou } \\
\text { regras no gerenciamento de resíduos eletroeletrônicos }\end{array}$ & $5 \%$ & $11 \%$ & $32 \%$ & $16 \%$ & $37 \%$ \\
\hline
\end{tabular}

Fonte: Os autores (2018).

O desenvolvimento dos estabelecimentos participantes em relação a práticas de gestão ambiental, refere-se mais a ações propriamente ditas que são aplicadas na empresa. $O$ andamento dessas práticas pode vir a refletir uma maior proatividade da empresa em relação a gestão dos REEE.

Os achados revelaram que existe uma quantidade razoável de empresas que não apresentam qualquer tipo de prática como campanhas, conscientizações ou priorização de fabricantes com políticas de pós-consumo, sendo que, de uma forma geral, a maioria das respostas em todos os itens concentrou-se nas respostas "Quase nunca" e "Algumas vezes".

Dentro da cadeia reversa de produtos, materiais ou bens de pós-consumo, é o nome dado a materiais que já esgotaram a sua vida útil e agora necessitam ser desmontados para recuperação ou para destinações finais como, por exemplo, aterro ou incineração (SOUZA; PAULA; SOUZA-PINTO, 2012). Sendo assim, fabricantes que possuem políticas pós-consumo são aqueles que junto com as assistências e comerciantes procuram encaminhar os REEE para as adequadas finalidades, sejam elas processos próprios na empresa ou encaminhando para outras empresas especializadas a fim de destinar adequadamente esses resíduos.

Os resultados obtidos, demonstraram que $16 \%$ dos sujeitos informaram que nunca priorizaram tais fabricantes ou fornecedores de peças com políticas de retorno pós-consumo, o que acaba por prejudicar todo o fluxo reverso dos REEE.

Em relação a práticas de educação ambiental com os funcionários, embora a maioria das respostas esteve entre "Quase Nunca" e "Algumas Vezes", foi obtido um melhor percentual em relação as outras práticas, o 
Revista Nacional de

Gerenciamento de Cidades

identificações dos geradores, coleta, transporte, acondicionamento e destinação final (SILVA; FERNANDES; MOTA, 2015).

Sendo assim, os planos de gestão de resíduos podem ser descritos como ferramentas administrativas desenvolvidas para a criação de um mecanismo de controle dos resíduos em todas as suas etapas no processo de produção, atuando no gerenciamento dos mesmos (SILVA, 2016), sendo esse um dos temas abordados nessa pesquisa (Tabela 3).

Tabela 3 - Desenvolvimento de um Plano de Gestão de Resíduos de Equipamentos Eletroeletrônicos.

\begin{tabular}{lccc}
\hline & Não implementado & Em Implementação & $\begin{array}{c}\text { Implementado e em } \\
\text { Manutenção } \\
\text { (Atualização) }\end{array}$ \\
\hline $\begin{array}{l}\text { Existência de um Plano de Gestão de } \\
\text { Resíduos Eletroeletrônicos (PGREEE). }\end{array}$ & $63 \%$ & $11 \%$ & $26 \%$ \\
\hline $\begin{array}{l}\text { Existência de reciclagem interna dos REEE } \\
\text { de forma a promover o reaproveitamento } \\
\text { de algum tipo de material dentro da própria } \\
\quad \text { empresa. }\end{array}$ & $63 \%$ & $11 \%$ & $26 \%$ \\
\hline $\begin{array}{l}\text { Existência de uma unidade específica de } \\
\text { armazenamento de REEE. }\end{array}$ & $42 \%$ & $32 \%$ & $26 \%$ \\
\hline \begin{tabular}{l} 
Fonte: Os autores (2018). \\
\hline
\end{tabular}
\end{tabular}

Fonte: Os autores (2018).

Os resultados demonstraram que existem empresas, embora representadas por uma minoria, em que havia um PGREEE e que estava sendo atualizado, representando uma preocupação desses estabelecimentos nessa temática. Porém, $63 \%$ dos sujeitos responderam que não foi elaborado o PGREEE nessas empresas, o que acaba por dificultar a logística reversa desses resíduos, considerando que a elaboração e a utilização dos planos, são instrumentos essenciais para uma gestão adequada dos resíduos.

A recuperação interna dos REEE, pode ser um dos principais meios de redução desses resíduos, atendendo alguns dos objetivos da PNRS, como a reutilização e a reciclagem, antes do encaminhamento para a sua disposição final (BRASIL, 2010). Contudo, essa prática não foi observada na grande maioria dos estabelecimentos participantes da pesquisa, sendo que $63 \%$ dos sujeitos informaram que não foi implementado reciclagem/reaproveitamento dos REEE gerados em seus locais de trabalho.

Para o ponto abordado na pesquisa sobre o armazenamento de REEE, embora não exista legislação específica no Brasil, é interessante observar outras normas que tratam de armazenamento de resíduos perigosos e não perigosos (ABNT, 1990, 1992), a fim de ter em mente certas medidas consideradas como boas práticas, para minimizar a possibilidade de impactos ambientais ou, até mesmo, na saúde pública, devido ao armazenamento inadequado desses resíduos.

Entre os sujeitos, $42 \%$ informaram que não apresentava qualquer tipo de armazenamento de resíduos no local, sendo descartados ou enviados para terceiros após o uso, porém $26 \%$ disseram ter uma unidade para armazenamento que estava sendo utilizada e em constante manutenção. 




\section{Revista Nacional de}

Gerenciamento de Cidades

Como proposta de um ponto de recebimento de REEE, o local que se mostra mais propício seria localizado em uma região central (Figura 2). Utilizando uma aproximação do mapeamento (Figura 1) para uma melhor visualização dos pontos onde os questionários foram aplicados e que estão sobrepostos na região central. A localidade sugerida para implantação desse PEV ficaria próximo a dois pontos onde foram realizados os levantamentos de dados, porém um desses locais seria o shopping, onde alguns dos resultados foram coletados (seis estabelecimentos), e que devido à proximidade das lojas não haveria como representar todas elas como pontos de coleta de dados, optando-se por representar apenas um. Dessa forma, o ponto de coleta de REEE seria próximo a sete estabelecimentos responsáveis por comercializar e gerar esse tipo de resíduo.

Figura 2: Proposta do ponto de recebimento de REEE na área urbana do município de Ponta Grossa

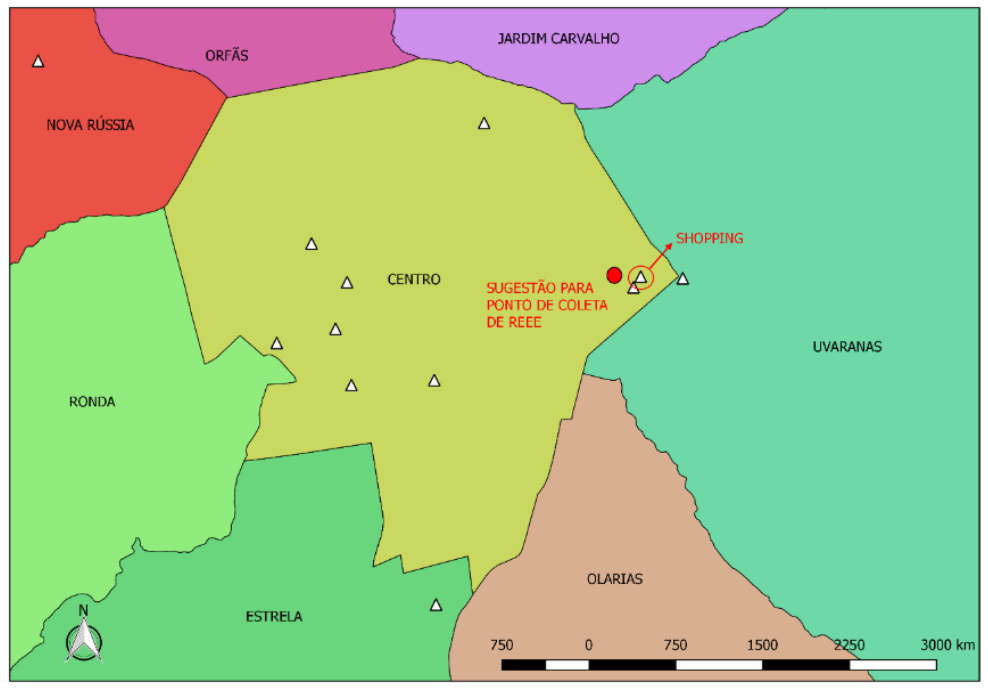

Fonte: Os autores (2018).

O local mostra-se interessante também, por se tratar do Parque Ambiental de Ponta Grossa, um local com intenso público, além de frequentemente possuir eventos culturais, festivais de food trucks, feiras de artesanatos e flores.

Um último detalhe que corrobora a proposta de localização do ponto de recebimento de REEE, seria a proximidade com o bairro de Uvaranas, correspondente ao bairro mais populoso da cidade, além de possuir uma avenida de grande movimento que liga o bairro ao centro, e que termina justamente no Parque Ambiental de Ponta Grossa.

É importante ressaltar que apesar do local proposto ser interessante diante das características ressaltadas, de acordo com o decreto no 10.240 , em seu art. 48 e parágrafo 2 , cada município atendido pelo sistema de logística reversa, deverá instalar no mínimo um ponto de recebimento a cada 25.000 habitantes (BRASIL, 2020). Sendo assim, o número de pontos de recebimento efetivamente necessário para atender a legislação com base na população da cidade, seria, aproximadamente, quatorze pontos de entrega. 


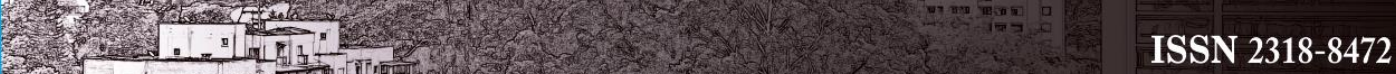

Revista Nacional de

Gerenciamento de Cidades

\section{CONCLUSÕES}

A partir da realização desse trabalho, foi possível perceber, que apesar do conhecimento por parte da população e comerciantes, as ações efetuadas neste setor ainda são incipientes, sejam elas na infraestrutura para receber e trabalhar com esse resíduo, nas técnicas de tratamento em nível comercial, ou até mesmo na divulgação de informações para população quanto a sua destinação. Algumas dessas falhas podem ser observadas pela falta de diversos pontos importantes para a gestão dos REEE, como a inexistência de um PGREEE na maioria dos estabelecimentos que participaram da pesquisa.

A gestão dos REEE nas assistências e comércios na cidade estudada, apesar de já existente quando considerados alguns fatores, como ações de educação ambiental e uma maior conscientização da população, ainda se encontra em construção no que diz respeito a ações concretas, sendo necessário novos investimentos no setor, a fim de promover mudanças e adequações em diversos pontos referentes a gestão desses resíduos. É interessante ressaltar, que apesar de tais questões serem apresentadas para um estudo local, diversas características desses problemas podem ser encontradas tanto em níveis municipais e estaduais quanto nacionais, porém, sempre respeitando as especificidades de cada região.

Outro fator importante para o sucesso da logística reversa dos REEE consiste no envolvimento e empenho de todos os responsáveis pelo fluxo reverso desses resíduos, para que as empresas, bem como seus clientes, possam começar a absorver e aplicar com maior eficiência estas medidas em seu cotidiano. Desse modo, é possível incluir também os municípios como fortes integrantes da logística reversa, onde, apesar de não existir uma obrigatoriedade regulamentada para com os municípios, o seu auxílio como gestor e agente de fiscalização de todos os integrantes da cadeia reversa propicia resultados que geram não apenas benefícios de cunho ambiental, mas também social, econômico e de saúde pública.

A partir de ações como a responsabilidade compartilhada dos diferentes atores, trabalhos intensivos de educação ambiental e o desenvolvimento, cada vez mais frequente, de legislações que apresentem diretrizes de como deve ser a forma de instrução para os integrantes da cadeia, é possível que os municípios caminhem para uma gestão integrada mais eficiente desses resíduos e que sejam adotadas práticas para um consumo consciente, propiciando a busca por um desenvolvimento mais sustentável.

\section{Agradecimento}

Agradecimento a Fundação Araucária pela concessão de bolsa para realização deste projeto.

\section{REFERÊNCIAS}

ACIPG, Associação Comercial, Industrial e Empresarial de Ponta Grossa. Guia de Negócios, 2018. Disponível em <https://www.acipg.org.br/guia/> Acesso em 10 nov. 2018

ALVES, V. C.; BARBOSA, A. S. Práticas de gestão ambiental das indústrias coureiras de Franca-SP. Gestão \& Produção, v. 20, n. 4, p. 883-898, nov. 2013.

ASSOCIAÇÃO BRASILEIRA DE NORMAS TÉCNICAS. NBR 11174: Armazenamento de resíduos classe II - não inertes e III - inertes. Rio de Janeiro, 1990.

ASSOCIAÇÃO BRASILEIRA DE NORMAS TÉCNICAS. NBR 12235: Armazenamento de resíduos sólidos perigosos. Rio de Janeiro, 1992 
ÁVILA, L. B.; SILVA, A. S. Instrumentos de apoio à gestão ambiental urbana. Revista Nacional de Gerenciamento de Cidades, v. 05, n. 36, 2017.

BALDÉ, C. P.; GRAY, V. KUEHR, R. STEGMANN, P. The Global E-waste Monitor 2017, 2017. Disponível em: <https://collections.unu.edu/eserv/UNU:6341/Global-E-waste_Monitor_2017_electronic_single_pages_.pdf > Acesso em 10 nov. 2018

BEDANTE, G. N.; SLONGO, L. A. O Comportamento de Consumo Sustentável e suas Relações com a Consciência Ambiental e a Intenção de Compra de Produtos Ecologicamente Embalados. In: Encontro de Marketing - EMA, 1. Atibaia, SP, 2004. Anais... Atibaia, ANPAD, 2004.

BEZERRA, A. P.X. G.; SANTOS, I. G. S.; LORENA, E. M. G.; GABRIEL, F. A.; HOLANDA, R. M. Percepção Ambiental de Funcionários de uma empresa Pública do Estado de Pernambuco Sobre Resíduos de Equipamentos Eletroeletrônicos. Educação Ambiental em Ação, v. 59, Ano VX, mar/mai 2017.

BRASIL. Política Nacional dos Resíduos Sólidos. Lei no 12.305, de 02 de agosto de 2010. Institui a Política Nacional de Resíduos Sólidos. Diário Oficial da União. Brasília, DF, 03 ago. 2010.

BRASIL. Ministério da Saúde. Conselho Nacional de Saúde. Resolução n. 466, de 12 de dezembro de 2012. Aprova diretrizes e normas regulamentadoras de pesquisas envolvendo seres humanos. Brasília, Diário Oficial da União, 12 dez. 2012.

BRASIL. Decreto № 10.240, de 12 de fevereiro de 2010. Regulamenta o inciso Vi do caput do art. 33 e o art. 56 da Lei no 12.305 , de 2 de agosto de 2010, e complementa o Decreto no 9,177, de 23 de outubro de 2017, quando à implementação de sistema de logística reversa de produtos eletroeletrônicos e seus componentes de uso doméstico. Diário Oficial da União, Brasília, DF, no 31,13 fev. 2020, Seção 1, p. 1.

BRASIL. IBGE. Censo Demográfico, 2010. Disponível em

<http://cidades.ibge.gov.br/xtras/perfil.php?lang=\&codmun=411990\&search=parana\%7cponta-grossa> Acesso em 12 jun. 2019.

CUI, J.; ZHANG, L. Metallurgical recovery of metals from electronic waste: A review. Journal of Hazardous Materials, v. 158, n. 2-3, p. 228-256, out. 2008.

FARINA, F. C Abordagem sobre as técnicas de geoprocessamento aplicadas ao planejamento e gestão urbana. Cadernos Ebape.BR, v.4 n. 4, dez 2006.

FERREIRA, L. S.; CÉSAR, A. S.; CONEJERO, M. A.; GUABIROBA, R. C. S. A voluntary Delivery Point in Reverse Supply Chain for Waste Cooking Oil: An Action Plan for Participation of a Public-School in the State of Rio De Janeiro, Brazil, Recycling, v. 3, n. 48 , out 2018.

GIL, A. C. Como Elaborar Projetos de Pesquisa. 4a ed. São Paulo: Editora Atlas S.A., 2002. 176 p.

GONÇALVES, F. M.; LEME, R. S. Logística Reversa: Qual é o papel dos municípios no cenário da Política Nacional de Resíduos Sólidos? Revista Jurídica da FA7, v. 15, n. 1, p. 63-87, jan/jun 2018.

HENRIQUE JÚNIOR, S. S.; MOURA, F. P.; CORREA, R. S.; AFONSO, J. C.; VIANNA, C. A. MANTOVANO, J. L. Processamento de placas de circuito impresso de equipamentos eletroeletrônicos de pequeno porte. Química Nova, v. 36, n. 4, p. 570-576, 2013.

LADEIRA, W. J.; MAEHLER, A. E.; NASCIMENTO, L. F. M. Logística Reversa de Defensivos Agrícolas: fatores que influenciam na consciência ambiental de agricultores gaúchos e mineiros. Revista de Economia e Sociologia Rural, v. 50, n. 1, p. 157-174, 2012.

MOTA, J. A.; GONÇALVES, M. G.; SANTOS, E. B. A.; KAKABANE, G. SANTOS, J. Comportamento do usuário no descarte de lixo eletrônico na zona sul da cidade de São Paulo. In: ENCONTRO INTERNACIONAL SOBRE GESTÃO EMPRESARIAL E MEIO AMBIENTE, 



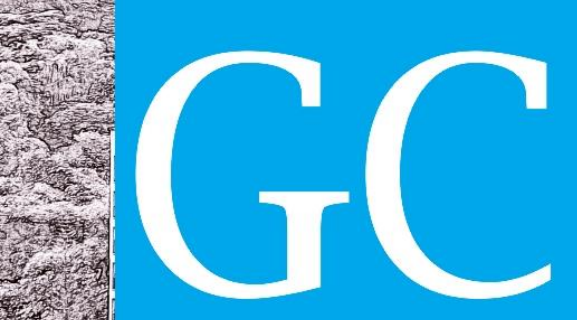

ISSN 2318-8472

v. 08, n. 58,2020

\section{Revista Nacional de}

Gerenciamento de Cidades

SELPIS, A. N.; CASTILHO, R. O.; ARAÚJO, J. A. B. Logística Reversa de Resíduos Eletroeletrônicos. Tékhne \& Lógos, v. 3, n. 2, jul 2012

SOUZA, M. T. S.; PAULA, M. B. SOUZA-PINTO, H. O papel das cooperativas de reciclagem nos canais reversos pós-consumo. Revista de Administração de Empresas, v. 52, n. 2, p. 246-262, abr. 2012.

TANSKANEN, P. Management and recycling of electronic waste. Acta Materialia, v. 61, n. 3, p. 1001-1011, fev. 2013.

TRUTTMANN, N.; RECHBERGER, H. Contribution to resource conservation by reuse of electrical and electronic household appliances. Resources, Conservaton and Reclycling,v. 48, n. 3, p. 249-262, set. 2006.

YAMANE, L. H. Recuperação de metais de placas de circuito impresso de computadores obsoletos através de processo biohidrometalúrgico. 2012. Tese (Doutorado em Engenharia) - Universidade de São Paulo, São Paulo, 2012. 